\title{
Reduction of Parasitic water Intake and Selection of Optimum Concentrations for Alumina Production at RUSAL Nikolaev Ltd., Ukraine
}

\author{
Vitaliy A. Prigarin* and Natalia V. Shirina \\ Nikolaev Alumina Refinery, LLC \\ 471 Oktybrskiy, Nikolaev, 54051, Ukraine
}

Received 14.05.2016, received in revised form 20.06.2016, accepted 03.08.2016

\begin{abstract}
In the environment of instable and constantly rising gas prices, energy expenses constitute 46 $\%$ of the prime cost of alumina of RUSAL Nikolaev Ltd. One of the reasons of increase of heat consumption and, accordingly, of the prime cost of the finished products is parasitic water intake at alumina production areas. A review of the situation created has allowed singling out the major issues in this trend:

1. Dilution of aluminate liquor at the Thickening and Washing Area during flocculant preparation for dosing into the thickeners.

2. Utilization of technical water for water wash and mechanical seals of pump units at alumina production areas. Part of the water is pumped with drowned pumps to the process tanks and thickeners, reducing concentration of aluminate liquor.

3. Dilution of aluminate liquor at the Precipitation Area during washing of filtering cloths of disk vacuum filters according to schedule.

4. MAX HT consumption at the Evaporation Area is held per spent liquor cubic meters, accordingly at increase of parasitic water intake in aluminate and spent liquor, reagent dosage increases.

Actions taken to reduce parasitic water intake and optimization of concentrations in alumina production have made it possible to save \$3,07 M in 2014.
\end{abstract}

Keywords: cash cost reduction, parasitic water, concentrations, specific consumption, factorial analysis.

Citation: Prigarin V.A., Shirina N.V. Reduction of parasitic water intake and selection of optimum concentrations for alumina production at RUSAL Nikolaev Ltd., Ukraine, J. Sib. Fed. Univ. Eng. technol., 2016, 9(6), 887-893. DOI: 10.17516/1999-494X2016-9-6-887-893.

(C) Siberian Federal University. All rights reserved

* Corresponding author E-mail address: Vitaliy.Prigarin@rusal.com 


\title{
Снижение ввода паразитической воды
}

\section{и подбор оптимальных концентрационных режимов глиноземного производства на ООО «НГЗ» (Украина)}

\author{
В.А. Пригарин, Н.В. Ширина \\ ООО «Николаевский глиноземный завод» \\ Украина, 54051, Николаев, пр. Октябрьский, 471
}

\begin{abstract}
В условиях нестабильных и постоянно повышающихся ценн на газ затраты на энергоресурсы составляют $46 \%$ от себестоимости глинозема НГЗ. Одним из источников повышения расхода тепла и, соответственно, себестоимости готовой продукции является ввод паразитической воды на участках глиноземного производства. Анализ сложившейся ситуачии позволил выделить основные проблемы по этому направлению:

1. Разбавление алюминатного раствора на участке сгущения и промывки при приготовлении флокулянта для дозировки в сгустители.

2. Использование технической воды на гидросмывы и механические уплотнения насосных агрегатов на участках глиноземного производства. Часть воды откачивается зумпфами в технологические баки и сгустители, снижая конщентрацию алюминатного раствора.

3. Разбавление алюминатного раствора на участке декомпозиции при промывке фильтрующих полотен дисковых вакуум-фильтров согласно графику.

4. Расход реагента МАХ НТ на участке выпарки ведется на $1 \mathrm{M}^{3}$ маточного раствора, соответственно, при увеличении ввода паразитической воды в алюминатный и маточный раствор увеличивается дозировка реагента. Реализация мероприятий по снижению ввода паразитической воды и оптимизации концентрационных режимов глиноземного производства, позволила получить в 2014 г. эффеккт в размере \$ 3,07 млн.
\end{abstract}

Ключевые слова: снижение себестоимости, паразитическая вода, конщентрационные режимы, удельный расход, факторный анализ.

В условиях высокой стоимости энергоресурсов, затраты на которые составляют 46 \% от себестоимости глинозема НГЗ, одним из приоритетных направлений является снижение энергозатрат.

В результате анализа структуры затрат в себестоимости готовой продукции были выявлены наиболее значимые факторы, влияющие на энергопотребление:

1. Поступление паразитической воды на участках глиноземного производства.

2. Концентрационные режимы глиноземного производства.

По каждому из факторов в результате проведенного анализа определены следующие проблемы и направления для улучшений.

Поступление паразитической воды на участках глиноземного производства:

- разбавление алюминатного раствора на участке сгущения и промывки красного шлама при приготовлении флокулянта для дозировки в сгустители;

- использование технической воды на гидросмывы и механические уплотнения насосных агрегатов на участках глиноземного производства;

- разбавление алюминатного раствора на участке декомпозиции при промывке дисковых вакуум-фильтров. 


\section{Концентрационные режимы глиноземного производства:}

- низкая концентрация разбавленной пульпы;

- высокая концентрация упаренного раствора.

По каждому из направлений были выработаны и реализованы мероприятия по снижению влияния факторов на энергопотребление.

\section{Разбавление алюминатного раствора на участке сгущения и промывки красного шлама при приготовлении флокулянта для дозировки в сгустители}

Для увеличения скорости и полноты разделения жидкой и твердой фаз при сгущении и промывке в сгустители и промыватели подается синтетический флокулянт, раствор которого готовится на воде; 80 \% паразитической воды, вводимой на участке сгущения, поступает при приготовлении флокулянта, 20 \% - на другие производственные нужды.

Показатель количества поступающей паразитической воды на участке сгущения оценивается по разнице концентраций растворов разбавленной пульпы и алюминатного раствора по $\mathrm{Na}_{2} \mathrm{O}$. Разбавленная пульпа из отделения выщелачивания насосами ППС подается на узел сгущения, где происходит отстаивание шлама, отделение жидкой фазы (алюминатный раствор) от твердой (шлам). При повышении доли боксита Гвинея «Киндия» в перерабатываемой корзине ООО «НГЗ» происходит увеличение количества образования шлама и, как следствие, увеличение расхода флокулянта, а значит, и количества вводимой с ним паразитической воды.

Для решения данной проблемы в ООО «НГЗ» был реализован комплекс мероприятий:

1. Проведение лабораторных испытаний по подбору и переходу на новый вид флокулянта НХ-3000 для снижения удельного расхода и, соответственно, снижения ввода паразитической воды с ним.

2. Проведение промышленных испытаний по подбору оптимальных дозировок нового вида флокулянта НХ-3000 для осаждения красного шлама.

3. Замена роторных расходомеров на узле приготовления флокулянта НХ-300 (3000).

4. В 2015 г. на стадии реализации проект «Перевод установок приготовления флокулянта 2-й стадии в CУ «Delta-V»» для автоматического управления расходами флокулянта и воды.

Реализация данных мероприятий позволила снизить разбавление алюминатного раствора на 0,5 г/л за счет снижения количества воды, необходимого для приготовления флокулянта.

Таблица 1. Расходные коэффициенты на 1 т глинозема

\begin{tabular}{|c|c|}
\hline Год & Расход флокулянта, кг \\
\hline 2012 & 0,5082 \\
\hline 2014 & 0,4076 \\
\hline 2015 (январь-май) & 0,3996 \\
\hline
\end{tabular}




\section{Использование технической воды на гидросмывы \\ и механические уплотнения насосных агрегатов \\ на участках глиноземного производства}

Часть воды откачивается зумпфами в технологические баки и сгустители, снижая концентрацию алюминатного раствора.

Для решения данной проблемы был проведен ряд мероприятий:

1. Минимизация расхода воды на гидросмывы, изменение схем и перенастройка трубопроводов зумпфовых линий, исключающие подачу паразитической воды на сгустители красного шлама.

2. Разработка, утверждение и введение в работу графиков контроля и проверки герметичности запорной арматуры на фильтрах ЭПАС.

3. Проведение обучения и проверки знаний технологического персонала на компьютерных тренажерах «Обработка фильтров МВЖ-250 и ЭПАС».

Реализация данных мероприятий позволила снизить разбавление алюминатного раствора на 0,3 г/л за счет снижения количества ввода паразитической воды, поступающей в растворы.

\section{Разбавление алюминатного раствора на участке декомпозиции при промывке дисковых вакуум-фильтров}

Для снижения количества используемой воды были изменены схемы промывки дисковых вакуум-фильтров путем установки форсунок. При промывке дисковых фильтров согласно гра-

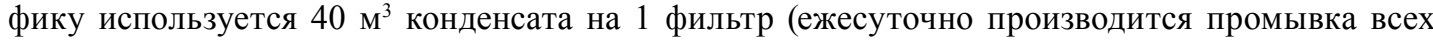
работающих фильтров).

На участке декомпозиции на линии конденсата установлены расходомеры для оперативного контроля за расходом воды и принятия корректирующих действий технологическим персоналом участка.

Реализация данных мероприятий позволила снизить разбавление алюминатного раствора на 0,2 г/л за счет снижения количества ввода паразитической воды.

Таким образом, системный подход к решению данной проблемы и реализованные мероприятия в ООО «НГЗ» позволили достичь следующих результатов:

- снижение разбавления алюминатного раствора на 0,6 г/л;

- снижение удельного расхода флокулянта на 0,14 кг/т;

- снижение разбавления маточного раствора на 0,8 г/л

- снижение удельного расхода реагента МАХ НТ на 0,015 кг/т за счет снижения ввода паразитической воды и снижения разбавления маточного раствора.

\section{Концентрационные режимы глиноземного производства}

Вторым направлением снижения себестоимости глинозема в ООО «НГЗ» стало изменение концентрационных режимов глиноземного производства. Концентрационные режимы установлены таким образом, чтобы обеспечивать пропускную способность оборудования под заданный план производства с соблюдением качественных характеристик готовой продукции.

Для снижения наиболее дорогого ресурса - теплоэнергии - были выполнены:

1. Разработка модели факторного анализа. 
2. Оценка сходимости расчетных и фактических величин.

3. Проведение лабораторных исследований

4. Поэтапное изменение концентрационных режимов.

5. Оценка фактической экономии.

Факторный анализ изменения концентрационных и технологических режимов позволил оценить максимально эффективные заданные режимы глиноземного производства и расход теплоэнергии на основных участках завода. Так, установленные нормативы по содержанию каустической щелочи в разбавленной пульпе в 2014 г. составили 146 г/л, в упаренном раствоpe -212 г/л.

При разработке модели факторного анализа были учтены все факторы, влияющие на расход теплоэнергии (рис. 1), что дало возможность оценить влияние каждого фактора на расход тепла и выделить наиболее ключевые факторы, а именно концентрацию алюминатного раствора и упаренного раствора.

С использованием данной модели появляется возможность математического прогнозирования изменения расхода теплоэнергиии в зависимости от изменения любого из показателей, в частности концентраций растворов. Данная модель в настоящий момент применяется для постановки плановых показателей и анализа текущего состояния.

Оценка сходимости расчетных и фактических величин осуществлялась на основе системы анализа SIS CAD, использование данного программного продукта позволило выявить наибольшие отклонения в расчетных и фактических величинах значений параметров и наиболее перспективные направления по снижению расхода тепла.

Параллельно с проведением анализа технологических параметров осуществлялись лабораторные исследования по влиянию повышения концентрации алюминатного раствора

\begin{tabular}{|c|c|c|}
\hline \multicolumn{3}{|c|}{ Исходные данные для расчета } \\
\hline Hapa6orka & 4096,8 & $\mathrm{~T}$. \\
\hline Na2Oк р.п. После Ва312 & & ris \\
\hline \multirow[t]{3}{*}{ Алюминатный раствор } & $\mathrm{Na} 2 \mathrm{OK}$ & $\Gamma / \pi$ \\
\hline & Arsфa k & ris \\
\hline & A.12O3 & $\Gamma / \pi$ \\
\hline Выккрутка (дек) & & $\%$ \\
\hline Выпррутка (упар) & & $\%$ \\
\hline \multirow[t]{2}{*}{ Маточный в растворе } & $\mathrm{Na} 2 \mathrm{OK}$ & rir \\
\hline & Arsфa k & ris \\
\hline Слабый раствор & $\mathrm{Na} 2 \mathrm{OK}$ & ris \\
\hline Упаренньй растворе & $\mathrm{Na} 2 \mathrm{OK}_{\mathrm{K}}$ & ris \\
\hline Козффициент выпаривания & & $T / T$ \\
\hline Удельньй вес мазточного (1.282) & $\mathrm{y}_{\text {I }}$ & $\mathrm{r} / \mathrm{cm} 3$ \\
\hline Удельныцй вес слабого (1.281) & $\mathrm{y}_{\text {म }}$ & r/cm3 \\
\hline $\mathrm{Y}_{\text {дельныгй вес упаренного (1.285) }}$ & $\mathrm{y}_{\text {I }}$ & r/cm3 \\
\hline Tеплосодержания пара & & $\Gamma_{\text {кал } / \mathrm{x} .}$ \\
\hline Возврат конденсата & & $\%$ \\
\hline Температура конденсата & & ${ }^{\circ} \mathrm{C}$ \\
\hline Затравочний гидрат, влага & & $\%$ \\
\hline $\begin{array}{l}\text { Количество алюминатного } \\
\text { раствора на тонну наработки }\end{array}$ & 12,63 & 12,89 \\
\hline $\begin{array}{l}\text { Количество маточного раствора } \\
\text { на тонну наработки }\end{array}$ & 12,01 & 12,20 \\
\hline Слабытй раствор & 12,01 & 12,20 \\
\hline $\begin{array}{l}\text { Количество выпаренной воды на } \\
\text { тонну наработки. }\end{array}$ & 3,63 & 3,70 \\
\hline Количество тепла на промыгви & & Гкал/т. \\
\hline $\begin{array}{l}\text { Колнчество теплознергнн на } \\
\text { выпарку , Гкал/т наработкн }\end{array}$ & & \\
\hline
\end{tabular}

Рис. 1. Исходные данные для расчета

$$
-891-
$$




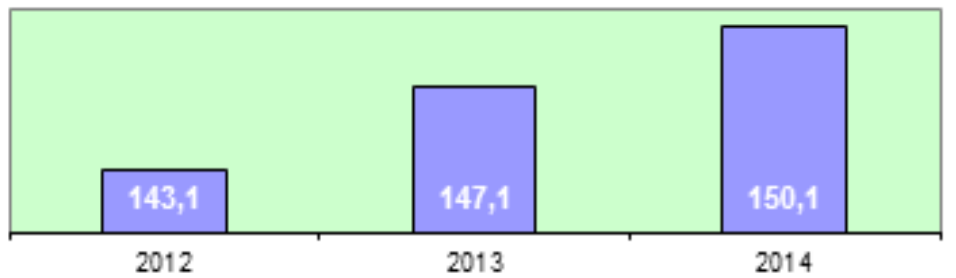

Рис. 2. Динамика повышения концентрации маточного раствора, г/л

на стойкость раствора и степень разложения ( \% выкрутки). Также исследовалась кинетика образования кристаллов в алюминатных растворах с различными уровнями концентрации.

Таким образом, были подобраны наиболее оптимальные соотношения концентрационных режимов, позволяющие при повышении концентрации алюминатного раствора сохранить уровень разложения алюминатного раствора на наиболее оптимальном значении. Следует отметить, что ранее не проводилось повышения концентрации из-за ограничений по производительности белой фильтрации, вызванного высоким содержанием оксалата в растворе.

При заданных концентрационных режимах отсутствовала возможность остановки выпарной батареи в резерв (КИ выпарных батарей в 1-м полугодии 2014 г. составил 89,3 \%), что приводило к повышенному расходу теплоэнергии.

Повышение концентрации активно начало проводиться в период сокращения объема производства, т. е. когда по фильтрации появился резерв, а также включения в этот период узла вывода оксалатов, позволившего снизить уровень оксалата и за счет этого также снизить нагрузку на узел фильтрации.

В этот период было проведено поэтапное повышение заданной концентрации разбавленной пульпы:

- этап 1 - с 146 г/л в начале 2013 г. до 147,1 г/л в конце 2013 г.

- этап 2 - с 147,1 г/л в начале 2014 г. до 150 г/л в конце 2014 г.

- этап 3 - снижение заданной концентрации упаренного раствора с 213,5 г/л в 2013 г. до 211,4 г/л в 2014 г.

Повышение концентрации алюминатного раствора оказало положительное влияние на кинетику декомпозиции раствора в начале процесса.

В результате контроля над процессом зародышеобразования гидроксида алюминия и более медленного разложения алюминатного раствора в «голове» процесса декомпозиции появились дополнительные возможности по управлению гранулометрическим составом товарного гидрата.

Изменение концентрационных режимов позволило выполнить пераспределение нагрузки теплопотребляющего оборудования (автоклавных и выпарных батарей) за счет уменьшения материальных потоков. Это обеспечило снижение коэффициента использования выпарных батарей во 2-м полугодии 2014 г. до 82,7 \%, что привело к снижению потребления теплоэнергии. 


\section{Выводы}

В результате реализованных мероприятий достигнут следующий экономический эффект:

- за счет изменения концентрации технологических растворов и снижения концентрации упаренного раствора в 2014 г. сэкономлено \$ 1,43 млн;

- за счет снижения ввода паразитической воды экономия равна \$ 1,64 млн;

- Суммарный эффект от реализации мероприятий составил \$ 3,07 млн.

Таким образом, реализация данных мероприятий позволила предприятию существенно снизить долю затрат энергопотребления в себестоимости готовой продукции без значительных капитальных затрат. 